TEMAS EM DESTAQUE - SEÇÃO TEMÁTICA / TEMAS SOBRESALIENTES - SECCIÓN TEMÁTICA

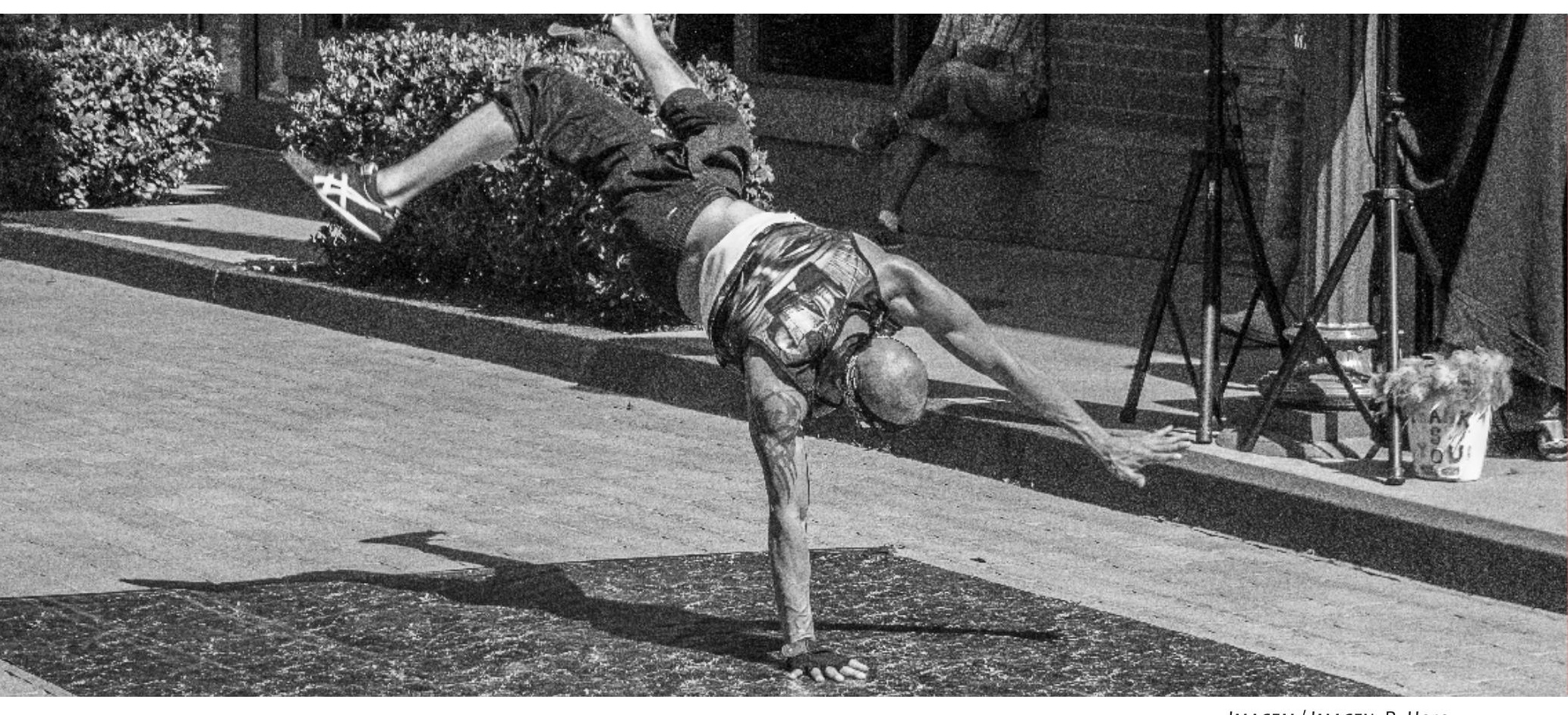

\title{
Adolescência e suas marcas: o corpo em questão
}

\section{Beatriz Akemi Takeiti}

Faculdade de Medicina e Programa de Pós-Graduação em Psicossociologia de Comunidades e Ecologia Social (EICOS), Universidade Federal do Rio de Janeiro - UFRJ, Rio de Janeiro, Brasil

https://orcid.org/0000-0003-2847-0787

\section{Cristiana Carneiro}

Faculdade de Educação e Programa de Pós-Graduação em Psicologia, Universidade Federal do Rio de Janeiro - UFRJ, Rio de Janeiro, Brasil

https://orcid.org/0000-0002-4042-1155

\section{Simone Ouvinha Peres}

Departamento de Psicologia Social, Universidade Federal do Rio de Janeiro - UFRJ, Rio de Janeiro, Brasil

https://orcid.org/0000-0001-7352-8664 
Este artigo nasce da preocupação central de sublinhar a importância da temática do corpo como objeto de estudo privilegiado para os campos da adolescência e juventude. Tem como objetivo, portanto, tecer uma discussão que o situa tanto como palco da existência do jovem na cidade e nas políticas, como construto teórico, chave para pensar a adolescência e a juventude em suas multidimensionalidades. O corpo se mostra e comunica sobre as formas de ser e estar no contemporâneo, mas também tece outros sentidos, expressa modos de vida, crenças e territórios. Assistimos a um verdadeiro crescimento de estudos sobre o corpo em que a preocupação com sua centralidade no âmbito da adolescência e da juventude se amplifica, tornando-o um objeto importante de reflexão sobre a condição humana, da vida social e contribui para a construção das identidades sociais (DEBERT; GOLDESTEIN, 2000; DEBERT, 2010).

Este estudo inicia trazendo uma discussão sobre a importância do corpo jovem no cenário da vida contemporânea no que tange aos aspectos mais amplos de sua participação como sujeitos de direitos e como aporte de uma pensabilidade de futuro.

É nesse bojo de discussões que aparece o corpo contemporâneo como superfície de troca e reconhecimento, um corpo imagem, um corpo designer, que se desenha e marca o espaço e tempo do agora, mas que também projeta um futuro. Marcar a pele nessa lógica de visibilidade passa a ser, em nossos tempos, um fenômeno que radicaliza a participação adolescente no cenário dos debates sobre o corpo. Marcas identitárias e de pertencimento, marcas de sofrimento psíquico e social, marcas como alvo das políticas públicas.

O texto prossegue debatendo como a compreensão biológica de desenvolvimento para o crescimento orientou os estudos pioneiros sobre corpo e adolescência numa espécie de paralelismo entre o orgânico e o psicológico. Esse último aspecto foi subsumido aos ritmos autônomos e invisíveis do primeiro. A crítica, posteriormente efetuada sobre essa matriz de pensamento que esquadrinhou o corpo em partes não comunicantes, inseriu os aspectos sociais e históricos como chaves de leitura importantes para a compreensão desse objeto.

Se, por um lado, o estudo do corpo se enraizou nos saberes disciplinares, por outro, é inequívoca a relação existente entre os diferentes saberes para o entendimento dos problemas hoje a serem enfrentados por adolescentes e jovens (BOZON, 2004; MALYSSE, 1998; RISCADO, 2009; RISCADO; PERES 2010).

\section{O corpo jovem na pólis, possibilidades de futuro?}

Takeiti e Vicentin (2017), ao refletirem sobre os modos de existência juvenil na periferia urbana da cidade de São Paulo, Brasil, tomaram um caso em particular - o de Jorge para evidenciar os acessórios da presença no cotidiano de um jovem - morador do distrito da Brasilândia e produtor cultural de saraus. Jorge, um jovem negro de pele clara, cisgênero, pobre, filho de trabalhadores - a mãe, baiana e diarista, o pai, mineiro e ajudante geral - nasceu e cresceu no distrito da zona norte da cidade de São Paulo, a Brasilândia, "berço da sua vida", mais especificamente num bairro chamado Jardim Icaraí.

Para Jorge, o território da Brasilândia, narrado em muitas linhas, vai se constituindo e se revelando num longo processo vivido, atravessado por muitas histórias - a história do seu bairro, as histórias de violência e subalternizações, de racismo, de amizades 
e a história do sarau da Brasa. Tal territorialização é inscrita na pele de Jorge, como se seu corpo comportasse a extensão de todas essas histórias e do espaço geográfico em que vivia. "Brasa", com letra cursiva, foi tatuado na região posterior do braço direito como uma marca que o revela e o evidencia como sujeito desse lugar. O nome Brasa também se constitui como uma política narrativa coletiva que produz outras inscrições - dos estigmas de ser da periferia, da atividade estética literária de inventar outros modos de estar no mundo. Afinal, Jorge foi um dos idealizadores do coletivo cultural Sarau Poesia na Brasa, um grupo cultural que produz e promove fruição estética literária, chamada literatura marginal na Brasilândia. Essa tatuagem, enquanto marca do lugar e dos empreendimentos coletivos, enquanto signo do território em que habita, produz estética e politicamente uma arte periférica que permite o uso de outras linguagens comunicantes.

Segundo Cavenacci (1990' apud DIÓGENES, 2008), o corpo se constitui como um mapa cultural que narra não apenas as histórias individuais, mas, sobretudo, uma dimensão cultural mais ampla. Corpo, palavra e, aqui, território se fundem em uma imagem visual, em signos de comunicação. Nessa direção, Diógenes (2008, p. 186) afirma que "exibir-se é uma forma de enunciar a existência e marcar sua presença no mundo". Jorge, ao tatuar "Brasa" no braço direito, não apenas chama atenção para o território geográfico ao qual pertence, mas também enuncia seu pertencimento cultural ao grupo do sarau e conjuga uma política narrativa coletiva que se singulariza através da marca em sua própria pele.

Diógenes (2008), ao estudar as gangues juvenis de Fortaleza, se refere às tatuagens como uma marca que as diferencia de outros jovens e constitui uma identidade em exposição, quase um sinal obrigatório. Para o autor, "o corpo marcado é também um corpo iniciado, um corpo entendido” (DIÓGENES, 2008, p. 189).

Jorge nos exorta a pensar no lugar do adolescente na cultura, na importância de seu próprio corpo, não apenas fazendo parte da cidade e seus territórios, mas de todo um projeto de nação juvenil: o corpo jovem como substrato da força de trabalho que irá construir o mundo que há de vir e que, para tanto, é palco de cuidados e investimentos; um corpo que cabe ao Estado educar e garantir sua integridade. Nos Parâmetros Curriculares Nacionais (PCN), educar abordando transversalmente "o corpo em sua dimensão erótica e reprodutiva e como fonte e matriz da sexualidade" (SANTOS, 2011, p. 52) tem sido tema de debates calorosos e de afirmações ideológicas quando se trata de corpos infantojuvenis (BRASIL, 1990).

O ideário do corpo jovem como território a ser resguardado, bem como aprimorado no contínuo temporal, parece razoavelmente tácito na atualidade, consolidado com a criação do Estatuto da Criança e do Adolescente (ECA), em 1990, e com o posterior Estatuto da Juventude, em 2013.

Objetivamente, nos marcos legais, o momento da adolescência e da juventude corresponde a idades cronológicas distintas para fins estatutários (a adolescência se inicia aos 12 anos e termina aos 18, e a juventude começa aos 15 e termina aos 29 anos). Neste artigo, não pretendemos aprofundar nas discussões teóricas sobre adolescência e juventude, embora saibamos de suas diferenças e especificidades. 
No entanto, somente tomar a adolescência e a juventude a partir da questão etária não é suficiente. Sabemos que um longo e trabalhoso percurso foi trilhado para a consideração cidadã desses sujeitos, ainda coexistindo práticas e pensamentos contraditórios em relação aos seus direitos e à sua participação. Nessa ótica, quando pensamos nos adolescentes e jovens de hoje, compreendemo-los tanto como parte integrante e importante daquilo que se passa no agora da pólis quanto como emblemas de investimento para o futuro da nação. As crianças, os adolescentes e os jovens são, na atualidade, não apenas considerados sujeitos de direitos, mas aportes de investimento para a construção de um futuro que se articula àquilo que definimos por civilização. O ideário de prevenção, por exemplo, projeta um futuro no qual a ideia de saúde engloba mais do que condições físicas ou simplesmente etárias e que dependerá do nosso contingente de jovens e crianças. As noções de cuidado e risco também denotam uma preocupação alicerçada em um depois.

Nesse campo de discussões, o corpo, na juventude e adolescência, também será considerado como eixo promotor e sustentáculo da dignidade da pessoa humana como fundamento do Estado brasileiro.

Retomando Jorge e suas marcas na pele como forma de presença no território, podemos apontar que essa superfície - pele -, além de suporte identitário, pode nos falar de tantas outras presenças juvenis que extrapolam o próprio território de origem. Retomando a ideia de risco como uma política voltada para o futuro, torna-se patente a preocupação em saúde mental com os cortes na pele relacionados à autolesão na juventude. Como podemos ler a partir do Sistema Único de Saúde (SUS):

As práticas de prevenção, a partir da instituição do SUS, estão vinculadas à concepção de que as condicionantes da saúde extrapolam os limites do corpo orgânico e se realizam na articulação do indivíduo com sua experiência no território, no contexto social onde vive. Em saúde mental, prevenção está articulada à ideia de saúde como resultante também das condições de vida (e não como antecipação de risco de doença) e, nesse sentido, sua reescrita pela noção de promoção de saúde mental tem sido a via mais promissora para construção de trajetórias efetivas na oferta de atenção (BRASIL, 2017, p. 5).

A palavra risco se insere em uma forma de se relacionar com o futuro relançando uma questão do agora no depois. Envolve, assim, toda uma probabilística e uma articulação com a noção de perigo, norteando ações de cuidado e atenção no agora com vistas ao futuro. Para Giddens (1992), a noção de risco se articula ao tempo e ao espaço exprimindo modos de colonização do futuro. Ainda que, como nos dizem Pereira e Souza (2007), seja um termo ambíguo e foco de grandes debates, a ideia de prevenção em saúde mental, por exemplo, extrapola e alarga uma visão de risco como apenas antecipação de uma possível doença, uma vez que pretende envolver a multifatorialidade das condições do viver.

O risco como construtor das condutas adolescentes é uma preocupação dos estudos atuais. O termo "condutas de risco" aplicado às jovens gerações reúne uma série de comportamentos que colocam os jovens simbólica ou realmente em perigo (LE BRETON, 2017). Para Le Breton (2017), as condutas de risco entre adolescentes e jovens, "dos jogos de morte ao jogo de vida", são mais do que um traço da adolescência, referem-se a uma individualização de comportamentos e normas de forma paralela a outras transformações da sociedade. A literatura mostra que essas condutas de risco remetem a diferentes motivações e podem estar associadas à dificuldade conhecida dos 
adolescentes de pensar nos riscos, fazendo com que o corpo tome a dianteira como uma forma de reação por uma conduta imediata que mais se parece um grito, uma marcação, um pedido de ajuda, uma forma de simbolizar ou uma passagem ao ato, como diriam os psicanalistas (LE BRETON, 2009).

No entanto, o próprio ideário de risco e a promoção de saúde coexistem no cenário das políticas e ensejam um debate acalorado entre os estudiosos, já que ensejam visões diferentes de desenvolvimento. Para além desse debate, que não é nosso mote central, cabe salientar que o corpo articulado às perspectivas de dignidade humana não poderá ser restringido a suas matrizes biológicas. Assim, para além do organismo, o corpo passou a ser indubitavelmente objeto concreto de investimento social e coletivo, suporte de ações e de significações, motivo de reunião e de distinção através de práticas e discursos abundantemente exaltados (LE BRETON, 2011).

Se, a partir do que introduzimos até aqui, parece evidente que o corpo na adolescência e juventude conseguiu certa visibilidade na pólis como objeto de atenção, cuidados, preocupações e direitos, ainda há grande dificuldade em abordar o corpo em sua multidimensionalidade, tanto nas políticas como nas práticas. Assim, esse grande campo de debates nos convoca a pensar na importância de questionar as formas acadêmicas de abordar o corpo adolescente na atualidade. Como pensar nas marcas na pele que se produzem hoje, como tatuagens, piercings e cutting, sem levar em conta a multidimensionalidade do corpo, que é carne, pele, secreções, mas também aporte identitário, sustentáculo da vida afetiva e social? Se as condicionantes da cidadania extrapolam os limites do corpo orgânico - ainda que o incluam - como pensar a adolescência e juventude sem levar em consideração a centralidade do corpo nessa reflexão?

\section{Do invisível biológico à superfície que se mostra: fronteiras da pele}

A pele se constitui no maior órgão do corpo humano, sendo responsável por cerca de $16 \%$ do peso corporal, é formada pela epiderme, que é a camada mais visível aos olhos, a derme e a hipoderme (ou tela subcutânea), que são as camadas mais profundas. A pele tem por função isolar as estruturas internas do ambiente externo, servindo também como proteção a outros órgãos (DOMANSKY; BORGES, 2012). Quando o indivíduo nasce, a pele ainda sofre transformações. A pele infantil ou jovem se apresenta como uma pele em formação, ou seja, uma pele sensível, com todas as suas estruturas de um adulto. Com a entrada na adolescência, a pele começa a sofrer alterações por influência hormonal, em que se destaca a atividade das glândulas sebáceas, e a resposta do sistema sensorial é altamente ativada (BERNARDO; SANTOS; SILVA, 2019; ROCHA; HORTA; SELORES, 2004). É através de estímulos à pele, de receptores táteis, que percebemos o toque, a pressão, a temperatura.

Se, nessa perspectiva mais orgânica, já é possível vislumbrar sua função em isolar estruturas internas do ambiente externo, a pele será compreendida aqui em sua função demarcatória. Nessa lógica demarcatória, o contemporâneo vai assistir a um movimento que a radicaliza, justamente porque escreve sobre essa função bio uma nova demarcação, seja por palavras ou imagens, como na tatuagem, seja nos cortes ou nas cirurgias plásticas. Ou seja, o corpo já não é uma versão irredutível de si, um corpo somente bio, mas uma construção pessoal, um objeto transitório e manipulável suscetível de mudanças segundo os desejos do indivíduo (LE BRETON, 2004). 
O corpo, entendido como universo signo, é representado através da aparência, dos movimentos e das sensações como um corpo que é comunicante, que deixa rastros de sentidos, onde a pele (a epiderme) adquire uma importante expressividade simbólica, bem como potencialidades performativas e sensitivas que são experimentadas pelos sujeitos ao limite. Com efeito, o corpo já não é mais encarado como um dado natural, matéria orgânica onde as modificações decorrem apenas do tempo biológico, pois o corpo adquiriu um potencial de mudança e exploração que lhe passou a ser intrínseco e ad infinitum. Nessa outra visão de corpo, o caráter identitário ganha um lugar de destaque.

As modificações e marcações corporais, como signo de identidade, são uma maneira de afirmar uma singularidade radical e atinge os jovens em seu conjunto como importante fenômeno cultural para toda uma geração. Sem se caracterizar como um fenômeno da moda, as tatuagens, os piercings, as diversas marcas corporais encarnam novos modos de identidade social, de gênero, pertencimento social e, ainda, novas formas de sedução (LE BRETON, 2004).

$\mathrm{Na}$ adolescência, o corpo torna-se um importante passaporte de acesso a um mundo de trocas afetivas, eróticas e emocionais e, principalmente, das interações que se inscrevem no domínio da sexualidade e da sedução (PAIS, 2012). Porém, para Le Breton (2017), o processo mais importante que ocorre é o de uma subjetivação, de uma apropriação simbólica de si em que os vários aspectos da construção de uma identidade estão em jogo. Ou, em termos mais enfáticos, diante das evidências da imagem corporal e das marcas, o conhecimento dos adolescentes sobre o repertório de insígnias passa a ser indicativo do valor de um jovem perante seu grupo, pois esse saber mostra o sólido conhecimento que ele possui sobre o repertório de marcas disponíveis junto aos seus pares. Assim, marcar e desmarcar o corpo é uma forma primordial de socialização, pois existir é o mesmo de ser notado, marcado e desmarcado. Por essa razão, "uma aparência que desagrada o grupo expõe à perda de prestígio permanente, à zombaria, ao desprezo e ao assédio" (LE BRETON, 2017, p. 109).

\section{A construção da identidade à flor da pele}

A pesquisa de campo empírica realizada no Departamento Geral de Ações Educativas (Degase-RJ) com adolescentes e jovens de 15 a 21 anos feita por uma grande equipe de pesquisadores e alunos das Universidade do Estado do Rio de Janeiro (UERJ), Brasil, da Universidade Federal do Rio de Janeiro (UFRJ) e do Instituto Fernandes Figueiras (IFF-Fiocruz), Brasil, em três unidades, duas masculinas e uma feminina, constatou em termos mais enfáticos evidências da importância da imagem corporal e das marcas presentes nos corpos dos entrevistados, bem como o conhecimento dos adolescentes sobre o repertório de insígnias e tatuagens que passam a ser indicativo do valor de um jovem perante seu grupo, principalmente no contexto dos jovens cujo destino foi ou ainda é a passagem pelo Degase.

Em campo se observou muitas diferenças de gênero na questão da marcação do corpo e das tatuagens feitas entre os próprios adolescentes homens e mulheres no que diz respeito à escolha da imagem da tatuagem, ao tipo de desenho de pinturas e aos locais escolhidos do corpo para receberem a tatuagem. As adolescentes - exemplificadas neste artigo - apontam no próprio corpo nomes próprios, siglas de nomes/apelidos, como PJL para designar "paz, justiça e liberdade", coração, flores, nomes de facções 
criminosas, como Terceiro Comando (TC) e Comando Vermelho (CV), artigo do Código Penal (157), imagens e fotos dos(as) namorados(as) ou dos(as) filhos(as), menos as que são feitas na cadeia, essas últimas não são facilmente mostradas.

A pesquisa feita em grupo com quatro adolescentes na Unidade Feminina - Joana, 16 anos; Nádia, 15 anos; Paula, 17 anos; e Telma, 14 anos - evidenciou que todas elas tinham nomes de ex ou atuais namorados(as), maridos ou companheiras tatuados, assim como de familiares. Essa prática é muito frequente, como também é a do auto ferimento, cortes, riscos/riscas, marcas dolorosas (ou não) feitas durante a internação, sobre as quais falaremos mais adiante.

Ao pedir às adolescentes que informassem quantas tatuagens tinham feito e com quantos anos fizeram a primeira, Telma (14) disse ter quatro e que a primeira foi feita aos 12 anos; Paula (17) falou ter três e que a primeira foi aos 15; Joana (16) tem ao todo 12 tatuagens, tendo feito a primeira aos 11 anos; Nadia (15) disse que tem apenas duas e que fez a primeira aos 13 anos. Joana interrompeu e disse que Nádia, na verdade, tinha três tatuagens, e não duas, já que colocou uma por cima da outra na intenção de apagar a primeira. Completou dizendo que também tinha mais uma pelo mesmo motivo: tentou esconder o nome de um ex-marido fazendo outra tatuagem (CASTRO et al., 2016).

Como Joana (16) era a que tinha mais tatuagens entre as quatro, foi pedido que ela contasse sobre cada uma. Citou uma pimenta na virilha, o nome da mãe no braço, o nome do pai nas costas, o desenho de uma flor com uma borboleta, uma frase no braço ("Livrai-me de todo mal, amém"), um diamante na perna e uma coroa com o nome Ângelo (ex-marido) no braço, mas desta havia se arrependido e feito uma flor de lótus por cima. Ela afirmou que a do diamante era a única que não tinha um significado, mas que a escolha do diamante se deu porque ela gosta de tudo que brilha. Nadia (15) diz que fez uma pena no braço em cima do nome do ex-marido, porque se arrependeu de ter feito a primeira. Segundo ela, o significado é liberdade.

Paula (17) e Joana (16), quando indagadas sobre a escolha dos lugares das tatuagens, explicaram que o importante é escolher lugares não comuns para assim se diferenciarem. Joana (16) diz que fez pássaros próximos aos seios, pois eles são grandes e quando ela coloca uma blusa fica chamando atenção. Afirma: "Ainda vou fazer outros pássaros descendo pela lateral da barriga, uma gaiola e um pássaro na porta gaiola com a frase: Deus é grande, existe, me fortalece e me guarda" (CASTRO et al., 2016, p. 26)

\section{Tatuagens de cadeia}

As tatuagens chamadas "de cadeia" feitas durante o cumprimento da medida socioeducativa são realizadas para esconder as mazelas, manchas ou "perebas" (terminologia empregada pelas meninas). Elas explicaram que as machas/perebas são frutos das tatuagens que elas mesmas fazem em si, as chamadas "tatuagens de cadeia" e que podem causar desconforto, inflamação, manchas, sumiços da pele. O motivo para se ferir está associado a razões como marcação, agonia, aflição, passatempo, dentre outros sentimentos e motivos. Quando perguntadas sobre quem mais faz esse tipo de tatuagem, todas atestaram que quase todas fazem. Eis a explicação do grupo da Joana, Nádia, Paula e Telma: 
Geralmente, rasgam (nós rasgamos) a pele profundamente com um copo descartável e colocam tinta de caneta. A tatuagem fica esbranquiçada devido à nova pele que nasce, mas com o tempo e com o sol, ela vai sumindo. Algumas vezes sangra e outras não, depende do lugar no corpo. Fazem em si mesmas e umas nas outras (CASTRO et al., 2016, p. 26).

Se toda essa discussão sobre a pele como superfície que se mostra e nos dá a ver como palco de identificações nos instiga a pensar nas subjetividades que aí estão sendo produzidas, é também a pele e suas marcas que fundamentam todo um modelo de atenção quanto à automutilação em adolescentes calcado sobre estudos epidemiológicos de grande escala. Assim, tanto a pele cifrada para um outro num cenário pessoal de identificações subjetivantes quanto a pele objeto bruto das estatísticas epidemiológicas podem nos dizer dos adolescentes e jovens. No contexto empírico estudado particularmente por uma das autoras deste estudo, dentre outras que participaram de um grande estudo (CASTRO et al., 2016; D’ANGELO; HERNÁNDEZ, 2017; HERNÁNDEZ et al., 2018; HERNÁNDEZ; CASTRO; D’ ÁNGELO, 2019), o das adolescentes em cumprimento de medidas socioeducativas foi observado não somente o uso da tatuagem como signo de identidade, mas também a prática de lesões auto infligidas feitas dentro e fora do sistema socioeducativo, além de outras importantes marcas identitárias, tanto como uma tendência social e grupal como modo de fabricação de si, de uma singularidade ou ainda como habilitando uma verdadeira manifestação de sofrimentos diversos. Nesse caso, o corpo é abjeto, abjeção que pode ser entendida, nesse contexto, como rejeição e sofrimento corporal frente a condicionantes sociais de existência. Nesse caso, algo se pronuncia à flor da pele, que fere, que produz chaga, que causa sensação ambígua de impressionar e desagradar, que trava um combate entre o tocar e o tanger a dor que fere. Essa dor pode vir da ofensa, da mágoa, da injúria, da punição, do castigo produzido que rompe no corpo o silêncio a provocar sofrimento ou raivas. Provocar marcas e sofrimentos em si mesmo, golpear-se, corta-se, doer-se, ressentir-se, condoer-se da prisão, do presídio, da jaula em que habita.

A pele em que habita os adolescentes, portanto, "fala" e nos indica que somente numa perspectiva ampliada de corpo poderemos ouvir melhor esse dizer, numa densidade que considere seu substrato somático, sua sociabilidade, bem como suas incursões psíquicas, políticas e culturais.

\section{Corpo e adolescência: para além de um paralelismo bio}

Para Papalaia e Feldman (2013), a passagem da infância para a vida adulta é marcada pela puberdade, com a maturação sexual de adolescentes e jovens. Para esses autores, a puberdade envolve alterações físicas dramáticas. Tais mudanças fazem parte de um longo e complexo processo de maturação que se inicia antes do nascimento e perdura por toda a vida adulta. Há a produção de vários hormônios, dentre os quais, a liberação de gonadotropina (GnRH) no hipotálamo eleva os hormônios luteinizante (LH) e o estimulador dos folículos (FSH). O aumento de FSH nas meninas leva ao início da menstruação. Nos meninos, o LH inicia a secreção de testosterona e androstenediona.

Toda essa orquestração hormonal, tão decisiva e central para os estudos sobre o organismo, ganha um aspecto preponderante nos estudos sobre puberdade. Todavia, parece acentuadamente insuficiente quando relacionada à demarcação da adolescência 
e juventude. A puberdade enquanto conjunto de modificações biológicas sistemáticas é mais universalizável, conquanto a adolescência e a juventude são construções historicamente datadas e circunstanciadas.

Para Le Breton (2007), nas nossas sociedades, a adolescência é o tempo necessário à domesticação de um organismo que muda, um pensamento renovado sobre o mundo, uma abertura ao outro, uma aprendizagem de ser homem ou mulher, uma crescente autonomia de movimento, um redespertar da sexualidade. Esse período vai das transformações da puberdade à entrada na vida adulta e traduz uma lenta transformação do sentimento de identidade através das experimentações dos jovens (LE BRETON, 2017).

Já o termo adolescência, na Psicanálise, surgiu contemporâneo à ênfase no primado da genitalidade, que teve Franz Alexander seu defensor mais radical, insistindo numa ideia de que o genital seria o objetivo de um tempo posterior, seria a finalidade para onde caminhariam as pulsões anárquicas da infância, portanto, um tempo de amadurecimento, de harmonização do psíquico. Tudo indica que o termo só teria sido utilizado a partir de 1923 e que primeiramente foi citado por Ernest Jones (ALBERTI, 1996). Essa ideia de genitalização como um fim melhor para o qual a adolescência se dirigia era absolutamente tributária à concepção evolucionista e à ideia de progresso, vertentes que a obra freudiana muitas vezes reafirmou.

Freud apoiou-se em uma visão de constituição filogenética do psiquismo humano segundo a qual poderíamos encontrar, no psíquico, marcas de outros momentos da evolução da espécie humana. Em Totem e Tabu, por exemplo, Freud [1913]/(1996)² se pergunta sobre a origem da civilização humana e descreve o mito como uma sequência linear e progressiva no desenvolvimento do social, no qual a família seria a fase mais evoluída da horda humana. Sua psicogênese da sexualidade, por sua vez, deu margem à compreensão de fases sequenciáveis do desenvolvimento, que corroborariam para uma maturidade genital correlacionada a uma tendência final para a organização da libido (FREUD, [1905]/1987a).

Se, no entanto, essa visão de genitalização foi talhada pelo pensamento psicanalítico, foi também a partir da Psicanálise que pudemos encontrar uma outra compreensão da adolescência. Ao postular a existência da sexualidade infantil e sua importância, Freud (1987a) rompeu com uma visão que associava sexualidade à puberdade. Nesse sentido, a sexualidade não seria uma prerrogativa do púbere e posteriormente do adulto, mas já estaria posta desde a infância e, ainda mais, a sexualidade infantil seria uma matriz fundamental do sujeito ao longo de toda a sua vida, o que significa dizer que ela perduraria por toda a vida. Isso nos dá a magnitude da importância do infantil em Psicanálise, o que, de certa forma, explica a pouca referência freudiana em relação à adolescência. Mais precisamente, Freud (1987a) se refere à puberdade, e não à adolescência, o que só vem a ser feito por trabalhos psicanalíticos posteriores (ALBERTI, 1996). Porém, ainda que a sexualidade infantil perdure por toda a vida, ela sofrerá modificações e não deixará de ser considerada um marco.

Nessa ótica, também possibilitada pela Psicanálise, "a infância não desaparece nunca, assim como nunca se alcança uma maturidade sexual absoluta, contraposta à sexualidade infantil. As organizações sexuais infantis estão contidas na adulta: seus elementos

2 A data entre colchetes indica o ano de publicação original da obra. Nas citações seguintes será registrada apenas a data da edição consultada pelas autoras. 
persistem, ainda que revalorizados ou ressignificados" (TUBERT, 1999, p. 13) numa configuração nova, diferente. Nessa visão, Freud se afasta do domínio da biologia e insere as manifestações somáticas na esfera intrapsíquica (ASSOUN, 1997). Essa nova configuração, favorecida pela puberdade, envolveria mudanças em relação à economia da libido, à diferenciação homem e mulher e à escolha do objeto sexual, ao reencontro do objeto perdido, à angústia infantil num grande palco que seria a revivescência do complexo de Édipo (FREUD, 1987a, 1987b). Porém, ainda que para a Psicanálise na adolescência se dê uma reedição do conflito edípico e que esse seja um ponto importante deflagrado pela puberdade, essa repetição se configura "sobre uma nova base, pois cada experiência vivida influi decisivamente no desenvolvimento posterior; os elementos de fases anteriores são retidos e, ao mesmo tempo, o novo não desloca o antigo, mas o transforma" (TUBERT, 1999, p. 13), o que colocaria em jogo a questão da sucessão. Se o novo e o antigo subsistem, não há como falar em sucessão linear, em que uma fase seria substituída por outra, deixando, assim, de existir.

É importante notar que não só se abre um campo de diferenças entre puberdade e adolescência, mas que há uma importante articulação entre ambas, convencionando ser a puberdade - fenômeno comumente estudado mais por seu viés orgânico - justamente a entrada para a adolescência. É também nessa dialética entre um organismo que funciona de forma parcialmente invisível, crescendo com seu sistema de regulações autônomas, e um sujeito que se desenvolve social e psiquicamente que foi sendo construída a categoria de adolescência.

Principalmente a Psicologia, mas também a Psicanálise e a Medicina, enquanto saberes que se ocuparam das origens da construção da categoria adolescência, fizeram-no principalmente calcadas sobre o ideário de maturação. Como podemos ler de um pioneiro da Psicologia, "a palavra 'adolescência' vem do verbo latino adolescere, que significa 'crescer' ou 'crescer para a maturidade" (HURLOCK, 1979, p. 2). Assim, o curso do desenvolvimento psíquico não contradizia o próprio curso da vida humana, que era entendido como uma "sequenciação sistematizável, ordenada segundo os princípios de complexidade e aperfeiçoamento crescentes" (CASTRO, 1997, p. 29).

Maturidade como finalidade de um tempo previsível, "no próprio consenso popular, a maturidade não é coisa que se conquista e, sim, coisa que se espera ou aguarda. Tradicionalmente, referimo-nos aos processos de maturação em termos de espera. Falamos em esperar ou em deixar amadurecer" (WEISSMANN, 1966, p. 11), ou seja, um tempo previsível, que bastaria passar. Nesse sentido, a vida humana deveria transcorrer fases que não só seriam encadeadas, sucessivas, mas que deveriam se ultrapassar. Mas, como já apontamos em outro trabalho (CARNEIRO, 2002), talvez a confusão do pensamento progressista foi identificar simetricamente crescimento com emancipação. Nesse pensamento, em que a história individual seguiria o mesmo caminho da evolução das espécies, o crescimento biológico passou a ser sinônimo de crescimento psicológico.

As ciências psicológicas passaram, então, a se preocupar com esse trajeto individual do mais primitivo ao mais evoluído, ou seja, da criança para o adulto. É nessa linha de direção que foi construída a ideia de desenvolvimento, de que a criança deveria crescer, não só de tamanho, mas intelectualmente, que deveria tornar-se mais forte, alargar-se, instruir-se. Vislumbrou-se um movimento psíquico simétrico ao físico, ou que, no mínimo, deveria acompanhar esse crescimento natural. Como podemos ler em Aberastury e Knobel (1970, p. 13), uma grande teórica do desenvolvimento, "as mudanças psicológicas que se produzem neste período, e que são a correlação de mudanças corporais [...]”. 
Nesse sentido, acreditava-se numa previsibilidade desse trajeto, pois assim como se sabia que, salvo nenhuma aberração, a criança se transformaria biologicamente num adulto, psiquicamente ela deveria adquirir aquisições e habilidades que também acompanhariam esse desenvolvimento.

Se toda essa discussão se deu na origem da construção da categoria adolescência, o final do século passado, nos diferentes campos de saber que se ocuparam da adolescência, assistiu-se a uma grande mudança nesse paralelismo mais estrito entre o biológico, o psicológico e o social.

Essa mudança nas concepções de corpo exerceu certa crítica ao paralelismo biológico. Numa visão mais histórica entendeu-se que cada sociedade, no interior de sua visão de mundo, produz um saber singular sobre o corpo, envolvendo seus elementos constitutivos, suas performances, suas correspondências, conferindo-lhe sentido e valor. Como afirma Le Breton (2003, 2007, 2009), nas mais diversas sociedades, o corpo tende a tornar-se a matéria-prima a ser modelada segundo o contexto do momento.

Ainda que um grande deslocamento das concepções de corpo articuladas à origem da construção da categoria adolescência tenha sido efetivado, as injunções do mercado e as novas formas de viver parecem relançar de outro modo um ideário bio. Na atualidade, as concepções sobre o corpo estão francamente ligadas ao avanço do individualismo, enquanto estrutura social, representado pela emergência de um pensamento racional, laico e, sobretudo, biomédico. Isso se torna mais evidente nas sociedades ocidentais, que pregam a liberdade individual. Ter um corpo e ser responsabilizado por ele, através do olhar biológico após a virada biopolítica (CASTIEL; DIAZ, 2007; ORTEGA, 2006, 2008), é mais importante do que ser o seu próprio corpo. Isso evidencia, conforme explica Le Breton (2007, p. 77), "o quanto o corpo estaria preso e subjugado ao espelho do social, marcando fortemente a convergência entre as performances sociais e identitárias a partir do forte controle estabelecido sobre as performances corporificadas".

A ênfase crescente dada ao corpo em nossa sociedade contemporânea, aos diversos procedimentos médicos e de cuidados corporais e higiênicos marcam as chamadas identidades somáticas, as bioidentidades, as quais representam o deslocamento para a exterioridade do modelo mais internalista e intimista de construção de si. Essa ação tem como pano de fundo alguns dos processos mais importantes que se constituíram a partir das mudanças que atingiram o paradigma da clínica moderna e suas respectivas concepções sobre saúde e doença, normal e patológico, bem como os efeitos dos discursos e práticas médicas associadas ao impacto crescente das biotecnologias na constituição dessa nova subjetividade submetida ao corpo (ORTEGA, 2008). Esse discurso vem propondo uma ideia de corpo que pode ser "consertado" por meio do medicamento. Um corpo ao qual se deve compensar a incompletude, ou seu "déficit", com técnicas e medicamentos apresentados como soluções ideais capazes de suprimir o mal-estar individual (LINDENMEYER, 2015). Para Vigarello (2016), o novo recurso ao corpo tornou-se a tentativa psiquicamente mais econômica de escapar da impotência e da dificuldade de pensar em si mesmo diante do incômodo de viver.

Retomando nossa discussão, como já delineado, a adolescência enquanto categoria de estudos teve em sua origem grande articulação bio/psicológica, amplamente questionada nos estudos posteriores, sobretudo quanto ao paralelismo desenvolvimental (CASTRO, 1997). Se, por um lado, o paradigma maturacional ligado aos ritmos biológicos parece razoavelmente já debatido, contemporaneamente, o corpo adolescente como objeto reinscreve uma articulação bio, que, a nosso ver, precisa de aprofundamento. Talvez não mais um paralelismo, mas um orgânico aparentemente mais controlável 
e moldável através dos avanços tecnológicos e farmacêuticos, subsumido ao que mostra a pele. Nessa nova lógica, as marcas adolescentes na pele como signos que, ao mesmo tempo que revelam, singularizam modos de pertencimento e distinção entre pares, afirmam identidades, possibilitando uma "verdadeira fabricação de si" ou ainda a "desmaternização" do corpo (LE BRETON, 2003). Assim, a "paixão do signo" significa entrar na cultura dos pares, no universo da imitação sob a égide do consumo, da imitação, como "um tipo de segundo corpo que vem protegê-los" (LE BRETON, 2017, p. 105).

Dessas provocações, afirmamos, aqui, um lugar de pensar o corpo não a partir dos paralelismos e fragmentações que os diversos campos de conhecimento atribuem a esse objeto, mas numa tentativa caleidoscópica de concebê-lo nas suas nuances e interfaces interdisciplinares, necessárias à compreensão dos estudos das adolescências e juventudes contemporâneas (JUPIASSU, 2006).

\section{À guisa de conclusão}

Iniciamos este artigo argumentando como o corpo jovem na atualidade conquistou certa visibilidade na cidade, sendo objeto de interesse e estudos. Essa presença se faz calcada numa proposta mais ampla de civilização, na qual esses corpos são compreendidos como sustentáculo de um depois e sobre os quais uma gama de direitos, atenção, cuidados e investimentos foram extensivos. Mas esse corpo que aparece na pólis é tanto único como universal, justamente apontando para as tensões que envolvem sua circunscrição como objeto.

Assim também podem ser lidas as marcas na pele, conquanto linguagens que tanto identificam os adolescentes como símbolos de pertencimento, quanto denotam um sofrimento que se escreve sobre a pele e que aparece nas estatísticas epidemiológicas. O corpo, então, nos conclama a pensar na intimidade e pessoalidade de um adolescente, bem como na expressividade de suas marcas em um grupo maior. Se essa multidimensionalidade do corpo adolescente pode, de certa forma, ser aludida no contemporâneo, o surgimento da categoria adolescência foi marcado por um forte paralelismo bio/psicológico.

Tecendo uma crítica a esse paralelismo e a relançando no contemporâneo, defendemos que o estudo do corpo se desenha numa via transversal no continente das ciências sociais, que cruza permanentemente outros campos epistemológicos (História, Antropologia, Psicologia, Psicanálise, Biologia, Medicina, Direito) diante dos quais espera-se que eles, conjuntamente, possam contribuir para o que é preciso conhecer sobre a problemática do corpo na adolescência. 
ABERASTURY, A.; KNOBEL, M. Adolescência normal: um enfoque psicanalítico. Porto Alegre: Artes Médicas, 1970.

ALBERTI, S. Esse sujeito adolescente. Rio de Janeiro: Relume Dumará, 1996.

ASSOUN, P. L. Corps et symptôme. Paris: Anthropos, 1997.

BAREL, A. O.; PAYE, M.; MAIBACH, H. I. (Ed.). Handbook of cosmetic science and technology. 3. ed. New York: Informa Healthcare, 2009.

BERNARDO, A. F. C.; SANTOS, K.; SILVA, D. P. Pele: alterações anatômicas e fisiológicas do nascimento à maturidade. Revista Saúde em Foco, Teresina, v. 11, n. 1, p. 1221-1233, 2019.

BOZON, M. Sociologia da sexualidade. Rio de Janeiro: FGV, 2004.

BRASIL. Lei n 8.069, de 13 de julho de 1990. Dispõe sobre o Estatuto da Criança e do Adolescente e dá outras providências. Brasília, 1990. Disponível em: <http://www. planalto.gov.br/ccivil_03/leis//8069.htm>. Acesso em: 20 ago. 2021.

Lei $n^{\circ} 13.438$, de 26 de abril de 2017. Altera a Lei $n^{\circ} 8.069$, de 13 de julho de 1990 (Estatuto da Criança e do Adolescente), para tornar obrigatória a adoção pelo Sistema Único de Saúde (SUS) de protocolo que estabeleça padrões para a avaliação de riscos para o desenvolvimento psíquico das crianças. Brasília, 2017. Disponível em: <http://www.planalto.gov.br/ccivil_03/_ato2015-2018/2017/lei//13438.htm>. Acesso em: 20 ago. 2021.

CARNEIRO, C. Tempo e destino no contemporâneo: uma leitura do sujeito através da adolescência. 2002. Tese (Doutorado) - Universidade Federal do Rio de Janeiro, Rio de Janeiro, 2002.

CASTIEL, D. L.; DIAZ, C. A. D. A saúde persecutória: os limites da responsabilidade. Rio de Janeiro: Editora Fiocruz, 2007.

CASTRO, L. R. Infância e adolescência na cultura do consumo. Rio de Janeiro: NAU, 1997.

CASTRO, P. O e S. et al. Relatório de pesquisa sexualidade na adolescência. Rio de Janeiro: Degase, 2016 (mimeo).

D'ANGELO, L. B.; DE GARAY HERNÁNDEZ, J. Sexualidade, um direito (secundário)? Atravessamentos entre sexualidade, socioeducação e punição. Plural, São Paulo, v. 24, n. 1, p. 78-104, 2017.

DEBERT, G. G. A dissolução da vida adulta e a juventude como valor. Horizontes Antropológicos, Porto Alegre, v. 16, n. 34, p. 49-70, 2010. Disponível em: <https://doi. org/10.1590/S0104-71832010000200003>. Acesso em: 20 ago. 2021.

DEBERT, G. G.; GOLDSTEIN, D. M. Apresentação. In: DEBERT, G. G.; GOLDSTEIN, D. M. Políticas do corpo e o curso da vida. São Paulo: Editora Sumaré, 2000. p. 9-14.

DE GARAY HERNÁNDEZ, J. ; BERTRAMI, L. Sexualidade, gênero e juventude: notas sobre experiências de pesquisa no sistema socioeducativo do Rio de Janeiro. Revista Eletrônica Interações Sociais, v. 2, n.1, p. 35-46, 2018.

DE GARAY HERNÁNDEZ, J. et al. Implicações éticas e metodológicas de uma cartografia no Sistema Socioeducativo: surpresas, angústias e caminhos possíveis. Revista de Ciências Humanas, Florianópolis, v. 52, 2018. 
DE GARAY HERNÁNDEZ, J.; CASTRO, P. O e S.; D’ANGELO, B. L. Educação em direitos sexuais e direitos reprodutivos: deslocamentos no sistema socioeducativo do Rio de Janeiro. Revista Interinstitucional Artes de Educar, Rio de Janeiro, v. 5, p. 46-67, 2019.

DIÓGENES, G. Cartografias da cultura e da violência: gangues, galeras e o movimento hip hop. 2. ed. São Paulo: Annablume, 2008.

DOMANSKY, C. R.; BORGES, L. E. (Org.). Manual para prevenção de lesões de pele: recomendações baseadas em evidências. Rio de Janeiro: Editora Rubio, 2012.

FERNANDES, A. I. P. Cuidados dermocosméticos para uma pele saudável: aconselhamento farmacêuticos nos casos mais comuns. 2012. 124 f. Monografia (Mestrado Integrado em Ciência Farmacêutica) - Universidade do Algarve, Faculdade de Ciências e Tecnologia, 2012.

FERREIRA, V. S. Atitudes dos jovens portugueses perante o corpo. In: CABRAL, M. V.; PAIS, J. M. (Coord.). Condutas de risco, práticas culturais e atitudes perante o corpo: resultados de um inquérito aos jovens portugueses em 2000. Lisboa: Celta, 2003. p. $265-366$.

FREUD, S. Três ensaios sobre a teoria da sexualidade. In: Edição standard brasileira das obras psicológicas completas de Sigmund Freud, v. VII. Rio de Janeiro: Imago, 1987a (Original de 1905). p. $17-198$.

. Totem e tabu. In: Edição standard brasileira das obras psicológicas completas de Sigmund Freud, v. XIII. Rio de Janeiro: Imago, 1996 (Original de 1913). p. 13-197. . Inibições, sintomas e ansiedade. In: Edição standard brasileira das obras psicológicas completas de Sigmund Freud, v. XX. Rio de Janeiro: Imago, 1987b (Original de 1926). p. 123-252.

GIDDENS, A. Modernidade e identidade. Rio de Janeiro: Jorge Zahar Editor, 2002.

HURLOCK, E. B. Desenvolvimento do adolescente. Tradução Auriphebo B. Simões. São Paulo: McGraw-Hill, 1979.

JUPIASSU, H. O espírito interdisciplinar. Cadernos EBAPE.BR, Rio de Janeiro, v. 4, n. 3, 2006. Disponível em: <https://bibliotecadigital.fgv.br/ojs/index.php/cadernosebape/ article/view/7401>. Acesso em: 20 ago. 2021.

LE BRETON, D. Adeus ao corpo: antropologia e sociedade. Campinas: Papirus, 2003.

Sinais de identidade: tatuagens, piercings e outras marcas corporais. Lisboa: Miosótis, 2004.

. A sociologia do corpo. Petrópolis: Editora Vozes, 2007.

Associados, 2009.

Condutas de risco: dos jogos de morte ao jogo de viver. Campinas: Autores . Antropologia do corpo e modernidade. Rio de Janeiro: Vozes, 2011.

Minas, 2017.

- Uma breve história da adolescência. Belo Horizonte: Editora PUC

LINDENMEYER C. Qual é o estatuto do corpo na psicanálise? Tempo Psicanalítico, Rio de Janeiro, v. 44, n. 2, p. 341-359, 2015.

MALYSSE, S. Em busca do corpo ideal. Revista Sexualidade, Gênero e Sociedade, Rio de Janeiro, n. 7 e 8, p. 12-17, 1998. 
ORTEGA, F. Corpo e tecnologias de visualização médica: entre a fragmentação na cultura do espetáculo e a fenomenologia do corpo vivido. Physis: Revista de Saúde Coletiva, Rio de Janeiro, v. 15, n. 2, p. 237-257, 2008. Disponível em: <https://doi.org/10.159o/S010373312005000200004>. Acesso em: 18 ago. 2021.

. Das utopias sociais às utopias: identidades somáticas e marcas corporais. In: ALMEIDA, M. I. M.; EUGENIO, F. (Org.). Culturas jovens: novos mapas do afeto. Rio de Janeiro: Jorge Zahar, 2006. p. 42-58.

PAIS, J. M. Sedução e sexualidade. In: Sexualidade e afectos juvenis. Lisboa: ICM, 2012. p. 121-144.

PAPALAIA, D. E.; FELDMAN, R. D. Desenvolvimento humano. 12. ed. Porto Alegre: AMGH, 2013.

PEREIRA, E. C.; SOUZA, M. R. Interface entre risco e população. In: ASSOCIAÇÃO BRASILEIRA DE ESTUDOS POPULACIONAIS. (Ed.). Textos completos de comunicações científicas, XV Encontro de Estudos Populacionais. Caxambu: ABEP, 2007. p. 18 - 22. Disponível em: <http://www.abep.nepo.unicamp.br/encontro2006/docspdf/ ABEP2006_592.pdf>. Acesso em: 20 ago. 2021.

RISCADO, L. C. Culto ao corpo: o significado da cirurgia estética entre mulheres jovens do Rio de Janeiro. 2009. 121 f. Dissertação (Mestrado) - Programa de Pós-graduação em Psicossociologia de Comunidades e Ecologia Social, Universidade Federal do Rio de Janeiro, Rio de Janeiro, 2009.

RISCADO, L. C.; PERES. S. O. Cultura da cirurgia estética e dominação masculina: uma análise a partir de mulheres jovens do Rio de Janeiro. Interseções, Rio de Janeiro, v. 12, n. 2, p. 342-357, dez. 2010.

ROCHA, N.; HORTA, M.; SELORES, M. Terapêutica tópica em dermatologia pediátrica, nascer e crescer. Revista do Hospital de Criança Maria Pia, v. 13, n. 3, p. 215-225, 2004.

SANTOS, B. R. Guia escolar: identificação de sinais de abuso e exploração sexual de crianças e adolescentes. Seropédica: EDUR, 2011.

TAKEITI, B. A.; VICENTIN, M. C. G. Periferias (in)visíveis: o território-vivo da Brasilândia na perspectiva de jovens moradores. Rev. Distúrbios da Comunicação, São Paulo, v. 29, n. 1, p. 144-157, mar. 2017. Disponível em: <https://doi.org/10.23925/21762724.2017v2gi1p144-157>. Acesso em: 18 ago. 2021.

TUBERT, S. A morte e o imaginário na adolescência. Rio de Janeiro: Companhia de Freud, 1999.

VIGARELLO, G. O sentimento de si: história da percepção do corpo, séculos XVI-XX. Petrópolis: Vozes, 2016.

WEISSMANN, K. A conquista da maturidade. Rio de Janeiro: Freitas Bastos, 1966. 
O presente artigo tem como objetivo refletir sobre a importância da temática do corpo nos estudos sobre adolescência e juventude. Corpo que faz presença na pólis tanto como palco de políticas públicas atuais de cuidado e atenção, como aporte de investimentos futuros. Também corpo expressivo que, através de suas marcas, pode nos falar de um campo simbólico para além de sua dimensão biológica. Por fim, corpo que problematiza a própria delimitação das categorias adolescência e juventude, apontando para a multidimensionalidade de sua compreensão.

Palavras-chave: corpo, adolescência, marcas corporais, interdisciplinar.

RESÚMEN

Palabras claves:

ABSTRACT

Keywords:

\section{Adolescencia y sus marcas: el cuerpo en cuestión}

Este artículo tiene como objetivo reflexionar sobre la importancia del tema del cuerpo en los estudios sobre la adolescencia y la juventud. Un organismo que está presente en la polis tanto como escenario de las actuales políticas públicas de cuidado y atención, como aporte a futuras inversiones. También un cuerpo expresivo que, a través de sus marcas, puede hablarnos de un campo simbólico más allá de su dimensión biológica. Finalmente, un cuerpo que problematiza la delimitación de las categorías de adolescencia y juventud, apuntando a la multidimensionalidad de su comprensión.

cuerpo, adolescência, marcas corporales, interdisciplinar.

\section{Adolescence and its marks: the body in question}

This article aims to reflect on the importance of the body theme in studies addressing adolescence and youth. The body is present in the polis not only in the scenario of current care and assistance public policies, but also as a contribution to future investments. In addition, there is the expressive body that, through its marks, provides us with a symbolic field beyond its biological dimension. Finally, there is the body that problematizes the delimitation of the adolescence and youth categories, indicating the multidimensionality of its understanding.

body, adolescence, body marks, interdisciplinary.

DATA DE RECEBIMENTO: 31/08/2021

DATA DE APROVAÇÃO: $11 / 10 / 2021$ 

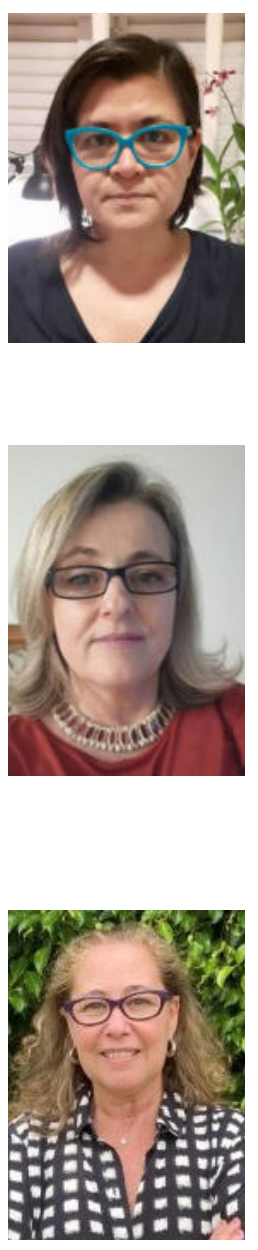

\section{Beatriz Akemi Takeiti}

Terapeuta Ocupacional, docente do Departamento de Terapia Ocupacional, Faculdade de Medicina e do Programa de Pós-Graduação em Psicossociologia de Comunidades e Ecologia Social (EICOS), Universidade Federal do Rio de Janeiro (UFRJ), Rio de Janeiro, Brasil.

E-mail: biatakeiti@medicina.ufrj.br

\section{Cristiana Carneiro}

Psicanalista. Pós-doutora, Paris VII. Professora Associada da Faculdade de Educação e do Programa de Pós-Graduação em Psicologia da Universidade Federal do Rio de Janeiro, Brasil. Coordenadora do NIPIAC e do Grupo de Trabalho da Associação Nacional de Pesquisa e Pós-graduação em Psicologia (ANPEPP) - Psicanálise e Educação.

E-mail: cristianacarneiro13@gmail.com

\section{Simone Ouvinha Peres}

Professora Associada do Departamento de Psicologia Social da Universidade Federal do Rio de Janeiro (UFRJ), Brasil. Mestre em Psicossociologia e Doutora em Saúde Coletiva.

E-mail:simoneoperes@gmail.com 